\title{
Investigation of the antioxidant activity of the peroxidase system of cell nuclei during germination of wheat embryos with different types of resistance to temperature stress
}

\author{
Gyulnar Vafina* \\ Ufa Institute of Biology-Subdivision of the Ufa Federal Research Centre of the Russian Academy of \\ Sciences, 450054, October prospect, 69, Ufa, Russian Federation
}

\begin{abstract}
The yield of agricultural crops directly depends on their ability to adapt to a constantly changing environment, the unfavorable climatic conditions of which cause oxidative stress, accompanied by the generation of reactive oxygen species in plant cells, which can cause damage to heteropolymer cell structures, thereby leading to suppression of plant growth and a decrease in productivity grains. It has been shown that the profile of the antioxidant activity of the peroxidase system in histone and non-histone blocks of structures (nucleoplasm, chromatin) of cell nuclei during germination is more pronounced in the cold-resistant variety Mironovskaya 808 (winter) compared to Mironovskaya yarovaya (spring), which correlates with the intensity of growth processes and can be associated with participation in the realization of proliferation and differentiation programs. A direct relationship between the scavenging of ROS and plant resistance to temperature stress, which is often associated with the increased activity of antioxidant enzymes that impart stress resistance to both high and low temperature stress, apparently also exists at the level of the plant cell nucleus.
\end{abstract}

\section{Introduction}

Plants are constantly exposed to various stress factors that affect their normal growth, productivity and survival. These unfavorable environmental conditions usually cause the accumulation of reactive oxygen species (ROS), which can cause severe oxidative damage to plants. In the course of evolution, plants have developed numerous protective strategies to remove free ROS from cells, thereby helping to reduce the impact of environmental stresses [1]. The concentration and nature of localization of various ROS in the cell carry out either damage caused by oxidative stress or redox signaling [2]. As you know, the cell nucleus, which controls morphogenetic developmental programs, is especially sensitive to the harmful effects of oxidation and at the same time it has precisely tuned redox signaling pathways [3]. Chromatin is a platform for a variety of cellular signals that influence gene expression. To date, the important role of redox intermediates in the regulation of DNA

* Corresponding author: vafinagh@mail.ru 
methylation, histone modifications, and chromatin remodeling has been proven, thereby being key regulators of epigenetic modifications in plants [4-6]. In plants, reactive oxygen species: hydrogen peroxide, hydroxyl radical, singlet oxygen and superoxide anion, formed in response to the reduction of oxygen molecules, affect the bioheteropolymer structures of the cell [7]. Due to the multitude of their mutual transformations, it is extremely difficult to distinguish between cytotoxic and signaling events caused by a specific ROS [8]. Hydrogen peroxide is considered one of the most important redox molecules due to its special physicochemical properties, including stability in cells, as well as rapid and reversible oxidation of target proteins [8]. It was shown that $\mathrm{H}_{2} \mathrm{O}_{2}$ is involved in cell differentiation and elongation, growth / division, aging and death, cell wall formation, regulation of enzymatic activity, synthesis of proteins and nucleotides, and expression of stress-sensitive genes [9]. In addition, $\mathrm{H}_{2} \mathrm{O}_{2}$ closely interacts with hormones, regulating plant development and stress responses [8]. It was shown that cytosolic $\mathrm{H}_{2} \mathrm{O}_{2}$ freely diffuses into the nucleus through nuclear pores [10], and is also transferred from chloroplasts to the nucleus [11]. Experiments with isolated tobacco cells have shown that plant nuclei are themselves an active source of $\mathrm{H}_{2} \mathrm{O}_{2}$ production [12]. The cell nucleus is a complex cellular organelle that constantly creates dynamic compartments inside itself, where functional processes segregate [13] and the coordination of various enzymes in different compartments in the process of regulating ROS levels in response to stress are issues that require further attention [14]. Thus, we can say that plants integrate ROS with genetic, epigenetic, hormonal and external signals, which contributes to their development and adaptation to the environment [8]. Understanding the processes of production, signaling and reduction of ROS is necessary to create resistant crops that are adapted to environmental conditions and resistant to pathogens.

The aim of this work was to study the localization and dynamics of the redox activity of the peroxidase system in non-histone and histone fractions isolated from nucleoplasm and chromatin during germination of spring and winter wheat seedlings.

\section{Methods}

Wheat seeds (Triticum aestivum L.) of varieties Mironovskaya 808 (winter variety) and Mironovskaya spring (spring variety) were used as the object of the study. Seeds were kindly provided by the collection of the "All-Russian Research Institute of Plant Industry". The wheat seeds were germinated at $22 \pm 1{ }^{\circ} \mathrm{C}$ in the dark. We have proposed a simple and effective method for the isolation and purification of cell nuclei using a glycerol gradient. Although further biochemical analysis is accompanied by a violation of the anatomy of the nucleus, we have developed a method of soft fractionation to separate the components of cell nuclei while preserving their individual functions.

Cell nuclei were isolated using the method described in [15]. Wheat germ was crushed in a jasper mortar for 60 seconds at a temperature of $0^{\circ} \mathrm{C}$ in homogenization medium: $20 \%$ glycerol, $0.02 \mathrm{M}$ triethanolamine (TEA-HCl) $\mathrm{pH} 6.8 ; 0.005 \mathrm{M} \mathrm{MgCl}_{2} ; 0.025 \mathrm{M} \mathrm{KCl} ; 0.003$ $\mathrm{M} \mathrm{CaCl}_{2} ; 0.005 \mathrm{M} \mathrm{NaCl} ; 0.004 \mathrm{M}$ n-octyl alcohol and $0.004 \mathrm{M} \beta$-mercaptoethanol. The homogenate was filtered through 4 layers of capron $(70 \mu \mathrm{m}$ pore size) and centrifuged at $1250 \mathrm{~g}$ for $20 \mathrm{~min}$. The sediment was transferred to a stepwise glycerin gradient consisting of 5 layers of glycerin $(50 \%, 60 \%, 70 \%, 80 \%, 90 \%$, w/v). Gradient centrifugation was performed at $1000 \mathrm{~g}$ for 1 hour. The sedimented nuclei were washed with $0.5 \%$ Triton X100 in the above medium (without glycerol), followed by centrifugation at $1250 \mathrm{~g}$ for 15 min. Then nuclei were washed twice in the medium: $0.005 \mathrm{M} \mathrm{MgCl}_{2} ; 0.025 \mathrm{M} \mathrm{KCl} ; 0.003$ $\mathrm{M} \mathrm{CaCl}_{2} ; 0.005 \mathrm{M} \mathrm{NaCl} ; 0.01 \mathrm{M}$ Tris- $\mathrm{HCl} \mathrm{pH} 6.8$ followed by centrifugation under the above conditions. The purity of the cell nuclei was controlled microscopically (Carl Zeiss Primo Star, Germany). 
Fractions of the cell nuclear were isolated from purified cell nuclei by increasing ionic strength of the solution. The nucleoplasm fraction was isolated with $0.14 \mathrm{M} \mathrm{NaCl}$. The fraction of chromatin loosely bound (Chromatin I) was obtained by extracting with $0.35 \mathrm{M}$ $\mathrm{NaCl}$. The fraction of chromatin tightly bound (Chromatin II) was extracted with $2 \mathrm{M}$ $\mathrm{NaCl}$. The nuclear matrix was obtained by extracting with $6 \mathrm{M}$ guanidine hydrochloride $(\mathrm{Gu} \cdot \mathrm{HCl})$ and $0.004 \% \beta$-mercaptoethanol [16]. The fraction of chromatin tightly bound (Chromatin II) was extracted by $2 \mathrm{M} \mathrm{NaCl}$. Fractions (Chromatin I and Chromatin II) differ by the ratio active and inactive genes; localization in the nucleus; sensitivity to action of dissociates substances, nucleases; ability to undergo conformation transitions [see 17]. Histone and non-histone proteins were obtained by chromatographic fractionation of supramolecular structures (nucleoplasm, chromatin I, chromatin II, nuclear matrix) on columns of Amberlite IRC-50 (Serva, Heidelberg). Amberlite IRC-50 was prepared using the method [18]. A protein of 20-50 $\mu \mathrm{g}$, dissolved in $6 \%$ guanidine hydrochloride on $0.1 \mathrm{M}$ potassium phosphate buffer $\mathrm{pH} 6.8$, was applied to column $(0.4 \times 4.5 \mathrm{~cm})$. The elution rate was $6 \mathrm{ml} / \mathrm{h}$. Exact concentrations of guanidine hydrochloride $6 \%, 8.9 \%, 10.6 \%, 13 \%$, $40 \%$ were determined using a linear gradient of guanidine hydrochloride $(6 \%-40 \%)$ for the yield of histone fractions. Preparative separation of nuclei proteins was carried out in discontinuous gradient of guanidine hydrochloride: $6 \%, 8.9 \%, 10.6 \%, 13 \%, 40 \%$ on $0.1 \mathrm{M}$ potassium phosphate buffer $\mathrm{pH}$ 6.8. Nuclear proteins were splited into 5 fractions, which according to the concentration of guanidine hydrochloride correspond to the fractions: nonhistone proteins, histone $\mathrm{H} 1$, histones $\mathrm{H} 2 \mathrm{~A}+\mathrm{H} 2 \mathrm{~B}$, histones $\mathrm{H} 3+\mathrm{H} 4$, and a histone residue $\mathrm{H} 3$ and $\mathrm{H} 4$ with an admixture of nuclear matrix proteins [18]. The peroxidase activity in the nuclear fractions was determined using benzidine (Reanal) as a hydrogen donor and hydrogen peroxide as its acceptor. To the $0.1 \mathrm{ml}$ of sample were added $2 \mathrm{ml}$ of $0.2 \mathrm{M}$ acetate buffer with $0.038 \%$ benzidine $\mathrm{pH} 4.7$ and $1.9 \mathrm{ml}$ of distilled water and after that was added $1 \mathrm{ml} 0.008 \mathrm{M} \mathrm{H}_{2} \mathrm{O}_{2}$. The formation of benzidine blue was measured at (Unico-2800, USA) at $610 \mathrm{~nm}$. Peroxidase activity was assessed in conventional units of the benzidine blue production per $1 \mathrm{~s} / \mathrm{mg}$ protein [19].

The experiments were repeated three times with at least three chemical repeats and two independent biological samples analyzed at each time. Data are presented as arithmetic means $+/$ - the standard deviation (SD). Research was conducted on the equipment of the center «Agidel»

\section{Results}

As you know, air-dry embryos are a highly differentiated organizm system that is at rest, and it was this stage that served as the starting point of the study. Figures 1-2 show the morphometric parameters of air-dry seeds $(0 \mathrm{~h})$ and seedlings $(24-48 \mathrm{~h})$ of the studied wheat varieties. In figure 1 shows that the winter variety has a higher seed mass than the spring variety. Seeds of approximately the same weight and size were selected for the experiment. In the process of germination of the embryos for the experiment, it was shown that the germs of winter wheat are ahead of the germs of spring wheat (24-48 hours) in terms of the growth of the coleoptile and the root system (figure 2). Only morphologically identical seedlings were used for this experiment. 


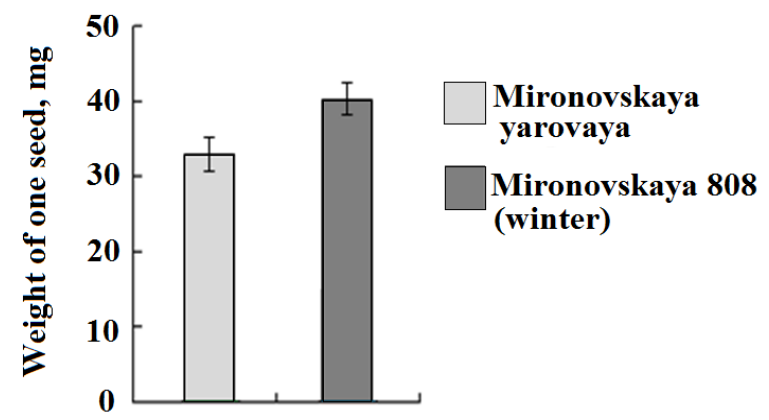

Fig. 1. Characteristics of air-dried seeds of spring and winter wheat.

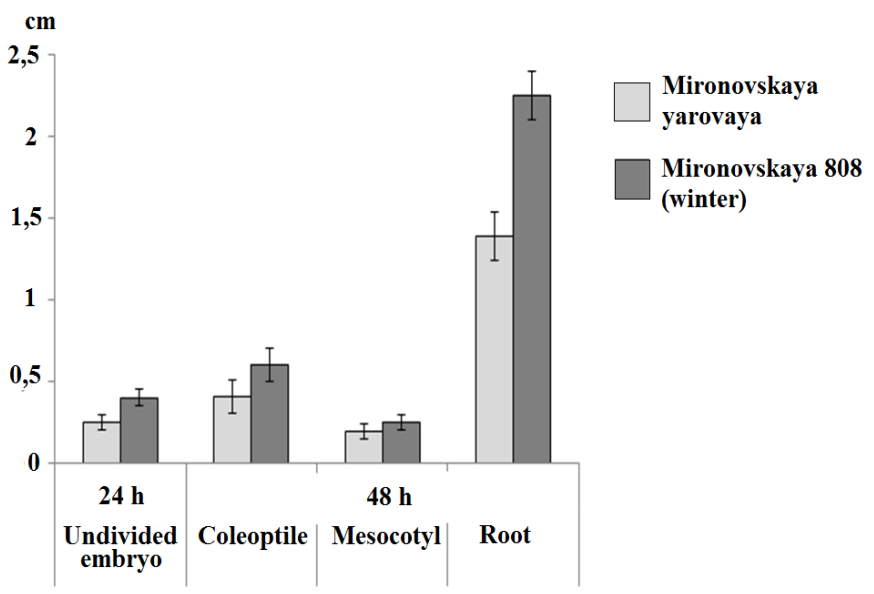

Fig. 2. Morphometric parameters of spring and winter wheat seedlings taken into the experiment.

An attempt to detect peroxidase activity in fractions of non-histones and histones isolated from nuclear suprastructures (nucleoplasm, chromatin, and nuclear matrix) revealed the features of the manifestation of enzymatic activity (figures 3-4) in different wheat varieties from the analysis of the figures it is obvious that the activity was found at the level of nucleoplasm and chromatin I-II. In the samples obtained from the nuclear matrix fractions, no peroxidase activity was detected. Analysis of figures 3-4 shows that a rather low level of peroxidase activity is maintained in air-dry embryos at the level of histones and non-histones in the nucleoplasm, chromatin-I and II. Further growth of seedlings is accompanied by an increase in the activity of peroxidases in the fractions of histones and non-histones of cell nuclei (24-48 h) at the level of the coleoptile and the root system. This trend persists in both the spring and winter varieties. The most significant differences between spring and winter varieties were found at the level of fractions of core histones isolated from the suprastructures of cell nuclei (nucleoplasm and chromatin loosely and tightly bound) (figures 3-4). 


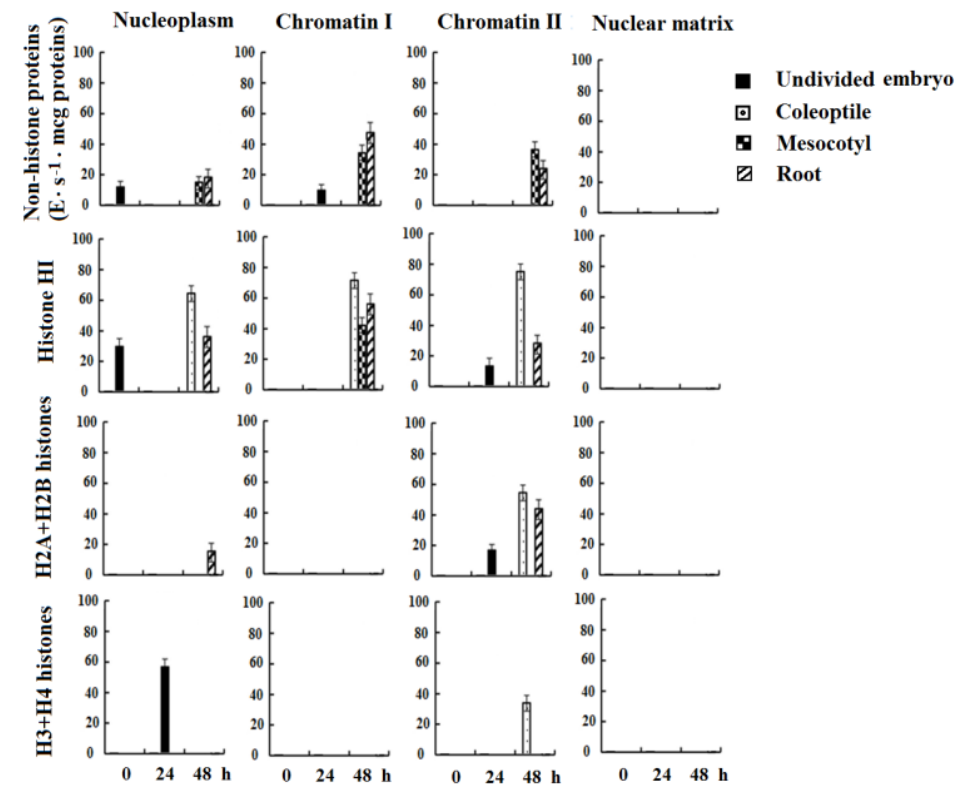

Fig.3. The redox activity of the peroxidase system in non-histone and histone blocks of the structures of cell nuclei: nucleoplasm, chromatin I, chromatin II, nuclear matrix in the process of germination of wheat cv. Mironovskaya yarovaya (spring).

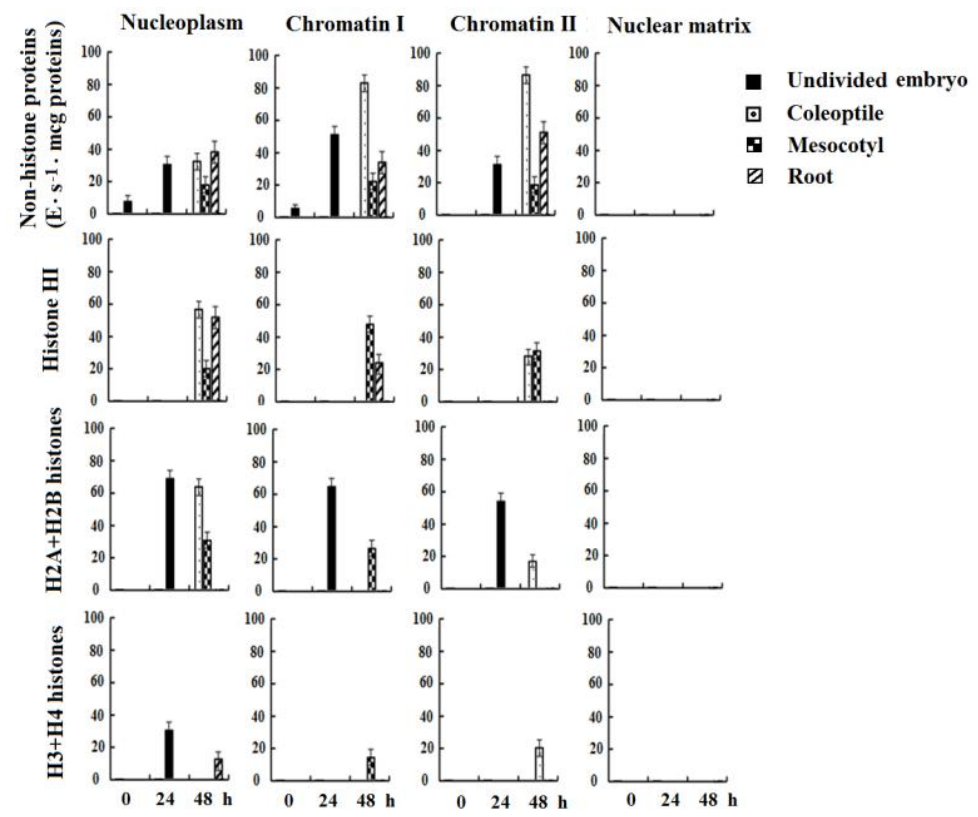

Fig.4. The redox activity of the peroxidase system in non-histone and histone blocks of the structures of cell nuclei: nucleoplasm, chromatin I, chromatin II, nuclear matrix in the process of germination of wheat cv. Mironovskaya 808 (winter). 


\section{Discussion}

It is known that ROS play a key role in the regulation of seed germination and dormancy, but the mechanisms of their action are still far from fully understood. Reactive oxygen species are continuously produced during seed development, from embryogenesis to germination, as well as during storage of seeds [20,21]. From the analysis of figures 3-4, it can be seen that air-dry embryos at the level of all suprastructures of the cell nucleus exhibited rather low peroxidase activity, which is apparently associated with a general limited metabolic activity and, therefore, ROS production is rather low [20]. However, in the process of soaking the seeds and during the germination of the embryo, metabolism is rapidly accelerated, which, apparently, correlates with an increase in ROS production by various pathways and in various subcellular compartments [9] and in the cell nucleus as well. As you know, the onset of growth processes occurs due to the elongation of cells. In dry mature seeds, the cells of the embryo are in the $G_{1}$ and $G_{2}$ states, however, cells in the $\mathrm{G}_{1}$ state predominate, apparently the least vulnerable state of the meristematic cell [22]. In wheat germ, the first mitoses begin at the root, then in the leaves, and after the root reaches $1.5 \mathrm{~cm}$ in the stem meristem [see 22]. This root length corresponds to $42-48$ hours from the beginning of seed soaking. The further growth of seedlings we observed was accompanied by an increase in peroxidase activity in the histone and non-histone fractions of cell nuclei (figures 3-4, 24-48 h) at the level of the coleoptile and the root system, which is apparently associated with a high content of hydrogen peroxide in the cell elongation zone $[8,23]$. It is known from the literature that cell division in the embryonic roots in the $G_{1}$ phase accelerates if they are in an oxidized state and slows down if they are in a reduced state; therefore, it can be assumed that regulated oxidation is a key feature of the early stages of the plant cell cycle [24]. It is likely that the redox state of the cell affects the realization of proliferation and differentiation programs. It is noteworthy that the varieties of spring and winter wheat taken into the experiment showed a difference in the profile of peroxidase activity at the level of histone and non-histone blocks of the suprastructures (nucleoplasm and chromatin) of the cell nucleus (figures 3-4). In general, the activity of the winter variety was more pronounced than that of the spring variety, which correlated with the intensity of growth processes. According to many authors [25], the intensity of growth processes, reflecting a complex of metabolic changes, can characterize the resistance of plants to environmental influences. It has been proven that there is a direct relationship between the absorption of ROS and plant resistance to temperature stress, which is often associated with the increased activity of antioxidant enzymes, which impart stress resistance to both high and low temperature stress $[7,26,27]$. As mentioned above, the transition from a dormant embryo to a metabolically active one associated with the onset of cell division is accompanied by a large-scale reorganization of chromatin. From figures 3 and 4 , it is obvious that the main differences in peroxidase activity between spring and winter wheat cultivars lie at the level of the histone core $(\mathrm{H} 2 \mathrm{~A}+\mathrm{H} 2 \mathrm{~B} ; \mathrm{H} 3+\mathrm{H} 4)$ in the nucleoplasm and chromatin loosely and tightly bound. It is known that histones are present in the nucleosome in the form of a tetramer: a pair H2A-H2B with a pair of histones $\mathrm{H} 3-\mathrm{H} 4$. Histones $\mathrm{H} 2 \mathrm{~A}$ and $\mathrm{H} 2 \mathrm{~B}$ are less stable in chromatin than $\mathrm{H} 3$ and $\mathrm{H} 4$, since they exchange different isoforms more easily and, perhaps, therefore, post-translational modifications in $\mathrm{H} 2 \mathrm{~A}-\mathrm{H} 2 \mathrm{~B}$ are less known than in more stable $\mathrm{H} 3$ and $\mathrm{H} 4$, however, a number of reports emphasize the importance of $\mathrm{H} 2 \mathrm{~A}$ and especially $\mathrm{H} 2 \mathrm{~B}$ in the dynamics of chromatin [see 28]. Redox control can influence oxidative post-translational modifications on histones and, in turn, the assembly of nucleosomes during DNA replication, thereby ensuring the transfer of epigenetic information during cell division or even modulating the differentiation of daughter cells [28-30]. In addition, low ROS levels are required for proper mitogenic signaling. ROS levels and the accumulation of oxidative damage in macromolecules vary 
throughout the cell cycle and increase during mitosis [31]. A growing body of research shows a close relationship between ROS metabolism and epigenetic regulation during plant growth and adaptation to the environment $[8,28]$. In this work, we tried to show the localization of peroxidase activity zones in the supramolecular structures of cell nuclei at the level of non-histones and histones, which are possibly part of an integrated ROS network for determining homeostasis and signs of stress in metabolic processes of the cell nucleus during plant growth and development [32].

\section{Conclusions}

It has been shown that the profile of the antioxidant activity of the peroxidase system in histone and non-histone blocks of structures (nucleoplasm, chromatin) of cell nuclei during germination is more pronounced in the cold-resistant variety Mironovskaya 808 (winter) compared to Mironovskaya yarovaya (spring), which correlates with the intensity of growth processes and can be associated with participation in the realization of proliferation and differentiation programs. A direct relationship between the scavenging of ROS and plant resistance to temperature stress, which is often associated with the increased activity of antioxidant enzymes that impart stress resistance to both high and low temperature stress, apparently also exists at the level of the plant cell nucleus.

The study was performed within the framework of the state assignment of the Ministry of Education and Science of the Russian Federation (075-00326-19-00) of the theme AAAA-A18-1180221901047.

\section{References}

1. E. Birben, U.M. Sahiner, C. Sackesen, S. Erzurum, O. Kalayci, World Allergy Organ J., 5, 1 (2012)

2. Y.M.W. Janssen-Heininger, B.T. Mossman, N.M. Heintz, H.J. Forman, B.Kalyanaraman, T. Finkel, J.S. Stamler, S.G. Rhee, F. van der Vliet, Free Radic Biol Med, 45, 1 (2008)

3. C. Lindermayr, E.E. Rudolf, J. Durner, M. Groth, Molecular Metabolism, 38 (2020)

4. M. Luo, G. Rios, T.J. Sarnowski, S. Zang, N. Mantri, J-B.Charron, M. Libault, Front. Plant Sci, 10 (2020)

5. M. Lukosz, S. Jakob, N. Buchner, T.C. Zschauer, J. Altschmied, J. Haendeler, Antioxidants \& Redox Signalling, 12 (2010)

6. V. Locato, S. Cimini, L.D.Gara, J. Experimental Botany, 69, 14 (2018)

7. K.K. Nadarajah,Int J. Mol Sci., 21 (2020)

8. H. Huang, F. Ullah, D-X. Zhou, M. Yi, Y. Zhao, Front. Plant Sci. 10 (2019)

9. V.D. Rajput, C. Harish, R.K. Singh, K.K.Verma, L. Sharma, F.R. Quiroz-Figueroa, M. Meena, V.S. Gour, T. Minkina, S. Sushkova, S. Mandzhieva, Biology, 10, 267 (2021)

10. L. Martins, J.A. Trujillo-Hernandez, J-P. Reichheld, Front. Plant Sci., 9 (2018)

11. F. Shapiguzov, J.P. Vainonen, M. Wrzaczek, J. Kangasjärvi, Front Plant Sci., 3 (2012)

12. C. Ashtamker, V. Kiss, M. Sagi, O. Davydov, R. Fluhr, Plant Physiology, 143 (2007)

13. O.L. Kantidze, S.V. Razin, Nucleic Acids Research, 48, 9 (2020)

14. V. Gautam, R. Kaur, S.K. Kohli, V.V. Verma, P. Kaur, R. Singh, P. Saini, S. Arora, A.K. Thukral, Y.V. Karpets, Y.E. Kolupaev, R. Bhardwa, Reactive Oxygen Species 
and Antioxidant Systems in Plants: Role and Regulation under Abiotic Stress (Springer, 2017)

15. E.A. Ivanova, G.H. Vafina, RF Patent, 1701747 (1991)

16. E.A. Ivanova, G.H. Vafina, RF Patent, 1733471 (1992)

17. G. Vafina, R. Ivanov, E. Ivanova, Acta Physiologiae Plantarum, 40 (2018)

18. E.A. Ivanova, G.H. Vafina, RF Patent, 2408602 (2011)

19. E.A. Ivanova, G.H. Vafina, RF Patent № 1733471(1999)

20. C. Bailly, H. El-Maarouf-Bouteau, F. Corbineau, Comptes Rendus Biologies, 331, 10 (2008)

21. C. Bailly, Biochem J., 476, 20 (2019)

22. K.N. Danovich, A.M. Sobolev, L.P.Zhdanova, I.E. Illy, M.G. Nikolaev, N.A. Askochenskaya, N.V. Obrucheva, E.E. Havkin, Physiology of seeds, (Nauka, Moscow, 1982)

23. J. Zeng, Z. Dong, H. Wu, Z. Tian, Z. Zhao, EMBO J., 36 (2017)

24. A. de Simone, R. Hubbard, N. Vinnegra de la Torre, Y. Velappan, M. Wilson, M. J. Considine, W.J.J. Soppe, C.H. Foyer, Antioxidants \& Redox signaling, 27, 18 (2017)

25. N.M . Karmanenko, Agricultural Biology, 5, 66 (2014)

26. M. Huang, Z. Guo, Biologia Plantarum, 49, 1 (2005)

27. R. Awasthi, K. Bhandary, H. Nayyar, Front. Environ. Sci., 17 (2015)

28. J.L. García-Giménez, C. Garcés, C. Romá-Mateo, F.V. Pallardó, Free Radical Biology and Medicine, 170 (2021)

29. K.T. Smith, J.L. Workman, PLoS Biol., 10, 7 (2012)

30. S. Kreuz, W. Fischle, Epigenomics, 8 (2016)

31. J. C. Patterson, B. A. Joughin, B. de Kooij, D.C. Lim, D.A. Lauffenburger, M.B. Yaffe, Cell Systems, 8, 2 (2019)

32. Y.Sun,Y. Lu, J. Saredy, X. Wang, C. Drummer IV, Y. Shao, F. Saaoud, K Xu, M. Liu, W.Y.Yang, X. Jiang, H. Wang, X. Yang, Redox Biology, 37 (2020) 